\title{
Is QUINEAN NATURALISM DEPENDENT ON THE METAMETALANGUAGE OF METAPHYSICS?
}

¿Depende El NATURAlismo Quineano Del Metametalenguaje DE LA METAfísica?

Pamela Ann J. Boongaling*

University of the Philippines, Diliman, Quezon City, Philippines. pamelaannnjose@gmail.com - pamela_ann.jose@upd.edu.ph

ReCibido el 26 de MARZo de 2020, APROBADo el 25 DE ABRIL DE 2020

\begin{abstract}
Resumen
I will demonstrate that Quinean naturalism must accommodate a priori truths in its epistemology if it aims to retain its naturalist stance. This happens because the laws of first-order logic which it uses in the regimentation of scientific theories are best perceived as metaphysical principles rather than logical laws. To support this position, I will demonstrate that since our best scientific theories are dependent on the meta-language of first-order logic and since the meta-language of first-order logic is included in the metametalanguage of metaphysics, science is also dependent on the metametalanguage of metaphysics. Hence, the cogency of Quinean naturalism's account of our best scientific theories must explain how science is dependent on the metametalanguage of metaphysics.
\end{abstract}

\section{Palabras Clave}

a priori, law of excluded middle, law of non-contradiction, metametaphysics, Quinean naturalism, Toumas Tahko.

\begin{abstract}
Demostraré que el naturalismo quineano debe acomodar las verdades a priori en su epistemología si pretende mantener su postura naturalista. Esto sucede porque las leyes de la lógica de primer orden que utiliza en la reglamentación de las teorías científicas se perciben mejor como principios metafísicos que como leyes lógicas. Para apoyar esta posición, demostraré que, dado que nuestras mejores teorías científicas dependen del metalenguaje de la lógica de primer orden, y dado que el metalenguaje de la lógica de primer orden está incluido en el metametalenguaje de la metafísica, la ciencia también depende del metametalenguaje de la metafísica. Por tanto, la contundencia de la explicación del naturalismo quineano de nuestras mejores teorías científicas debe explicar cómo la ciencia depende del metametalenguaje de la metafísica.
\end{abstract}

\section{KEY WORDS}

a priori, ley del medio excluido, ley de no contradicción, metametafísica, naturalismo quineano, Toumas Tahko

\footnotetext{
* (D) orcid.org/0000-0001-7236-4960
} 


\section{Introduction}

Roger Gibson (2000) claims that Quinean naturalism (henceforth QN) can be understood in terms of its three major components: naturalism, empiricism, and physicalism. ${ }^{1}$ He further claims that amongst these components, the hallmark of $\mathrm{QN}$ is its adherence to naturalism (Gibson, 2000). Hence, if our best scientific models show that we need to change QN's epistemology, methodology, and/or ontology, provided that we adopt QN's view that we should resort to science to determine what we ought to believe, our position can still be considered as a form of QN (Gibson, 2000). Therefore, this paper will supply my argument for the necessity of modifying QN's epistemology and its views regarding the relationship of science and metaphysics. ${ }^{2}$ My argument takes the following form:

(P1) Accepting the principle of bivalence requires us to commit to both the law of excluded middle and realism $(\mathrm{QN})$.

(P2) The law of excluded middle can be derived from the law of non-contradiction.

(P3) The law of non-contradiction is a fundamental metaphysical principle from which other principles can be derived as it claims that nature is ruled by consistency (Tahko, 2009).

(P4) If (P2) and (P3), the law of excluded middle is a metaphysical principle.

(P5) If (P1), (P3), and (P4), then commitment to the principle of bivalence is dependent on metaphysical presuppositions regarding the external world.

(P6) Since (P4), the meta-language of first-order logic is based on the metametalanguage of metaphysics.

(P7) Since (P6), science is based on the metametalanguage of metaphysics.

(C) An account that aims to provide a cogent description of the conceptual scheme of science and its objects must accommodate metaphysical laws in science for it is the only means that can explain why scientific knowledge is partially based on metaphysical laws.

\footnotetext{
${ }^{1}$ Peter Hylton (2007) describes Quine's physicalism as the view that "there is no difference without a physical difference" (314). This coincides with Roger Gibson's (2000) description of physicalism as Quine's hypothesis that "there is no difference in matters of fact without difference in the fulfilment of the physical-state predicates by space-time regions" (27).

${ }^{2}$ Quinean naturalism is equated with an anti-metaphysical position in the sense that it disparages the possibility of a non-scientific attempt to develop a system of thought about the external world.
} 
This argument merits an exposition and analysis for at least three reasons. First, it shows that the usage of first-order logic (henceforth FOL) as the meta-language of science cannot merely be based on its utility in the theoretical regimentation of scientific theories since its fundamental laws reflect the metaphysical principles that science must necessarily presuppose in order for it to prove its initial physicalist hypothesis regarding the external world. ${ }^{3}$ A part from this, it supplies a reassessment of the role of metaphysics within QN. Although W.V.O Quine (1969) maintains that metaphysical problems are pseudo-problems which should either be dispensed with or reformulated as scientific problems, the argument above shows otherwise. Such is the case, for it provides us with cogent grounds to establish that metaphysical truths can be found in the conceptual scheme of science. Finally, in conjunction with the previous rationale for this paper, the aforementioned argument demonstrates how QN can be formulated in such a way that it can accommodate a priori truths in its epistemology through its recognition of the separation and interdependence of metaphysics and science.

\section{Establishing the Dependence of Quinean Naturalism on the Metametalanguage of Metaphysics}

Let us begin by showing the dependence of QN on the metametalanguage of metaphysics. To do this, I will expound on the argument I provided in the previous section. The exposition of this argument will be divided into two parts. First, I will discuss the standard interpretation of QN's views regarding the role of FOL in scientific representations. From there, I will identify the problems with QN's views regarding the role of logical laws in our scientific theories. For the sake of simplicity, from this point onwards, let us refer to the object-language of FOL in our discussion (i.e. scientific theories) as $L_{0}$ and the meta-language of FOL as $L_{1}$.

It is important to note, at the onset, that Quine's (1961) justification for his usage of $L_{1}$ to regiment $L_{0}$ is purely based on pragmatic grounds.

\footnotetext{
${ }^{3}$ If we look at Quine's physicalism, there are at least two aspects that are emphasized. First, physical and abstract objects exists and second, the value of an object simply lies in its inclusion in a theory (Hylton, 2007). If we look at it this way, his physicalism does not seem to be dependent on a theory's relation to the external world. Yet, this is arguable on two fronts. First, his claim that the adoption of the principle of bivalence leads to the adoption of realism shows otherwise. Second, as I will demonstrate in this paper, since his position leads to the view that science is dependent on the metametalanguage of metaphysics and since metaphysics, in this view, aims to provide us with picture of the external world then it would not be amiss to maintain that his physicalism is also dependent on a perceived relationship between a scientific model and the external world.
} 
Amongst the repercussions of this position, our discussion will focus on how this led QN to state that logical laws are natural laws. Let us begin by providing a general characterization of how the standard interpretation of QN envisions a scientific theory.

Within QN, a scientific theory is seen as a network of interconnected statements whose logical form and relations are set by the syntax of $L_{1}$ and whose semantic content are derived from the data that we receive from our sensory experiences. This intricate connection between the syntax and semantics of our scientific theories is best shown in terms of the relationship between the principle of bivalence (henceforth $\mathrm{PB}$ ) and the law of excluded middle (henceforth LEM). Such is the case, for accepting PB requires us to accept both LEM and realism. ${ }^{4} \mathrm{~PB}$, in this sense, allows us to see how a regimented theory creates a principle that requires us to accept the conjunction of one of the primary laws of $L_{1}$ and the presupposition that its empirical data can be related to the mind-independent external world.

To demonstrate this relationship, let us begin by providing a formulation of $\mathrm{PB} . \mathrm{PB}$ states that given a statement $\mathrm{A}$, either ( $\mathrm{A}$ is true) $\mathrm{v}$ (-A is true). We can see here PB's dependence on LEM for LEM ensures the logical truth of statements with the form A v -A in a regimented theory. We can also see here that $\mathrm{PB}$ requires us to commit ourselves to the truth of realism for it presupposes that the truth-value of $A$ is dependent on the state of affairs in the external world. Note, however, that within QN even if $\mathrm{PB}$ presupposes that the semantic content of $\mathrm{A}$ has a connection to the state of affairs in the external world (i.e., due to its adoption of realism), the connection is not determined via a singular statement's correspondence to its truth-maker in external reality. In QN, a statement's truth-value is dependent on its inclusion in a scientific model that has predictive and explanatory power. For this reason, only when we have ascertained the predictive and explanatory power of a theory can we confirm the truth-value of its statements. We can see here QN's adherence to confirmational holism, the view that the confirmation that a theory receives extends to all the statements within it equally.

\footnotetext{
${ }^{4}$ There are two ways in which we can try to situate Quine's position in the realism/antirealism debate. In the first sense we can characterize realism via a theory's mind dependence/ independence from us. In this context, Quine is an anti-realist since he maintains that "objects are posits that we introduce as part of our theoretical activities" (Fogelin, 2006: 38). In the second sense, we can characterize realism as the position that accepts the principle of bivalence. It is in this context that Quine claims that accepting the principle of bivalence involves accepting realism (Hylton, 2007). This is so, for using and accepting PB commits one to the concept of truth (Dummett, 1994).
} 
What is important to note at this juncture is that QN's adoption of confirmational holism allows it to claim that logical laws are natural laws. Such is the case since, in a regimented theory, the laws of $L_{0}$ are contained in $L_{1}$. Since a successful theory is able to show that its contents are confirmed by empirical evidence then both the natural laws and the logical laws within it are confirmed either directly or indirectly by empirical data (Mittelstaedt and Weingartner, 2005). In effect, since their truth-value is justified in a similar manner, logical laws become natural laws (Mittelstaedt and Weingartner, 2005). We can see this more clearly if we return to the relationship of PB and LEM. PB sets the grounds that will allow us to establish the link between our observation statements and their empirical justification. Hence, when a theory is confirmed, the confirmation of its observations statements extends to the confirmation of PB. In a similar manner, since PB deductively entails LEM then the truth of PB leads to the truth of LEM.

Let us now demonstrate how this standard interpretation of QN falls short. One of the reasons for this can be traced to its characterization of the relationship between $L_{1}$ and $L_{0}$. As I see it, Quine (1961) is mistaken in claiming that the usage of $L_{1}$ on $L_{0}$ should only be based on pragmatic grounds. My reasons are as follows. First, the revision of a regimented theory cannot dispense with $L_{1}$ and second, the necessity of $L_{1}$ is required by QN's adherence to physicalism. The conjunction of these two points will show that QN ought to adopt $L_{1}$ due to what I refer to as procedural and theoretical grounds.

We can derive the procedural reason for the necessity of using $L_{1}$ on $L_{0}$ from James Harris' (1997) claim that QN is unable to recognize that statements of different logical levels in our scientific theories must have different logical types. To understand this, let us return to QN's usage of confirmational holism. The other side of confirmational holism is that observation statements can initiate changes within the interconnected statements in a theory that may, in the most extreme scenarios, require the revision of its logical and theoretical laws. The problem for QN then is, if such a need occurs, theoretical revision can only proceed if it continues to use $L_{1}$ in the assessment of the original version of the regimented theory. For example, it needs $L_{1}$ 's rules of inference to show that there is a contradiction between the new observation statements and the contents of the contested theory. If such is the case, then our reason for adopting $L_{1}$ cannot merely be based on purely pragmatic grounds for $L_{1}$ is indispensable in enabling theoretical changes in science. From 
this, we can also claim that it would be remiss to classify logical laws as natural laws for the former occupies a distinct level from natural laws in our scientific theories.

On a different note, we can also support Harris' (1997) argument for the necessity of using $L_{1}$ on $L_{0}$ by focusing on $\mathrm{QN}^{\prime}$ s theoretical claim that science adopts physicalism as its initial working hypothesis regarding the external world. What is crucial to emphasize here is the dependence of physicalism on our pre-theoretical intuitions regarding external reality. They are pre-theoretical intuitions, for instance, since they are based on our pre-evidential assumptions that there is an external world and its composition is partly physical in nature (Tahko 2016). Since they are pre-theoretical intuitions, the question we must address now is where does science derive the concepts and categories that it will use to assess its pre-theoretical physicalist intuitions regarding external reality.

It is at this juncture that we can now introduce Tahko's (2009) view that LNC can be considered as the most fundamental metaphysical principle that governs external reality. Tahko describes LNC as the principle that claims that "the same attribute cannot at the same time belong and not belong to the same subject in the same respect" (Tahko, 2009: 34). He adopts Aristotle's version of LNC since it places emphasis on "the mutual exclusiveness of having a certain attribute and lacking that attribute at the same time" (Tahko, 2009: 34). Now, Tahko (2009) demonstrates, through inference to the best explanation, the metaphysical status of LNC as he describes how the composition of the macrophysical world requires consistency based on our scientific theories. He states:

\begin{abstract}
Our observations suggest that an electric charge is a property than an entity can have in two different varieties: the positive and the negative. What suggests that this is a universal (and actual) condition-apart from the fact that we have never observed an entity that both has and does not have a charge at the same time-is that the causal powers associated with electric charges could not arise if the same entity could both have and not have a charge at the same time. For instance, atoms would not hold together... (In this, we can see that) macrophysical existence requires stability...(Hence), (t)he law of non-contradiction, if it is true, is perhaps the most fundamental condition of this type. (Tahko, 2009: 35)
\end{abstract}


It may be pointed out at this juncture that if we support LNC via inference to the best explanation of the contents of our best scientific theories then it seems that science's starting point for its theoretical constructions (i.e. its initial physicalist hypothesis) cannot be supported by LNC for the scenario that we have set so far seems to lead to an infinite regress. Yet, it is crucial to recognize that metaphysical principles can still occupy the role that we have attributed to them earlier (i.e. as the basis of physicalism) since these principles, even in their initial separation from scientific evidence, provide us with the possible conditions of the external world that reflect our pre-theoretical intuitions about it (Tahko, 2016; Morganti and Tahko, 2017). We can already see this in how LNC encapsulates our pre-theoretical intuition that it is possible that the macrophysical world is governed by consistency. On a different note, we can also see this in LEM. Note that we can also consider LEM as a metaphysical principle since it can be derived from LNC. ${ }^{5}$ The difference between both principles, however, can be seen in their formulations. Whereas LNC emphasizes that an entity cannot have mutually exclusive properties at the same time, LEM emphasizes that our description of these entities in the external world and their relations cannot both be true and false at the same time.

Now, one of the important repercussions of claiming that LNC and LEM are metaphysical principles is that it leads to the characterization of $L_{1}$ 's principles as a "sub-category of metaphysical principle(s)" (Tahko, 2009: 44). This shows us that $L_{0}$ must necessarily use $L_{1}$ based on theoretical grounds. That is, $L_{0}$ can only establish the starting point of all its inquiries (i.e. its initial physicalist hypothesis) if it adopts the metaphysical principles of $L_{1}$. Apart from showing the theoretical necessity of using $L_{1}$ on $L_{0}$, this also shows us that $L_{0}$ is also dependent on the metametalanguage of metaphysics (henceforth $L_{2}$ ). Such is the case for the principles of $L_{1}$ are contained in $L_{2}$. On a different note, it is also important to emphasize that this gives us another argument that can be the basis for our claim that logical laws are not natural laws, for in this scenario, logical laws ought to be characterized as metaphysical principles.

As an aside, our demonstration of $L_{0}^{\prime}$ s containment in $L_{2}$ above may initially be seen to be completely at odds with QN for it seems to require

\footnotetext{
${ }^{5}$ We can derive LEM from LNC, and vice-versa. This can simply be demonstrated this way: from $\sim(p \cdot \sim p)$, we can derive $\sim p \mathrm{~V} \sim \sim \mathrm{p}$ via De Morgan's theorems, from $\sim p \mathrm{p} \sim \sim \mathrm{p}$, we can derive $\sim p \mathrm{~V}$ $\mathrm{p}$ via Double Negation, and from $\sim \mathrm{p} V \mathrm{p}$, we can derive $\mathrm{p} V \sim \mathrm{p}$ via Commutation.
} 
QN to adopt modal logic. Yet, Tahko's (2009) description of modal logic shows otherwise. He claims that despite logic's usefulness in allowing us to represent the structure of reality, we cannot rely on it completely to accomplish the task of metaphysics (i.e. to determine the fundamental structure of the world) (Tahko, 2009). He states:

\begin{abstract}
(I)f metaphysics is about mapping the fundamental structure of reality, then logic...is about representing the results formally. When we reason about, say, matters of possibility and necessity, we are interested in the modal constraints that the structure of reality imposes on different kind of entities. Modal logic, for instance, is metaphysically interesting only insofar as it reflects these constraints... A very natural idea concerning the different systems of modal logic is that they reflect the different uses of 'necessity' and 'possibility' in our language. But this leaves the question about modality in the world completely unanswered. (Tahko, 2009: 45)
\end{abstract}

As per this claim, we can maintain that QN may continue to adopt its negative stance regarding modal logic and focus on determining how metaphysical and scientific hypotheses and theories may support one another in terms of their attempts to formulate scientific theories with greater predictive and explanatory powers.

At this point, we have established (P1) to (P7) of the argument that I outlined in the prior section. I have shown that $\mathrm{PB}$ is dependent on LEM, LEM is another formulation of LNC, and both LNC and LEM are best perceived as metaphysical rather than logical laws. In the process of doing these, I have also provided a general account of how LNC and LEM guide our scientific inquiries. All of these combined allowed us to establish that $L_{0}$ is dependent on $L_{2}$. With these in mind, the points I raised in this section showed that an account that aims to provide a cogent description of the conceptual scheme of science must accommodate metaphysical laws in science for it is the only means that it can show that scientific knowledge is partially based on metaphysical laws. In effect, it also provides us with an argument to support the view that QN can only provide a cogent description of how science can model reality if it accommodates metaphysical laws as a priori truths in its epistemology for it is the only means that it can show that scientific knowledge is partially based on metaphysical laws. 


\section{An Argument for the Non-inclusion of Scientific theories in the Metametalanguage of Metaphysics}

In this section, I will address a possible counterargument to my position. This counterargument targets (P6) to (P7) of the argument I outlined in the initial part of this paper. Recall that these premises take the following form. Since LEM is s metaphysical principle then the meta-language of first-order logic is based on the metametalanguage of metaphysics. Hence, science is based on the metametalanguage of metaphysics.

To offset this position, one may claim that the procedural and theoretical grounds for the necessity of using $L_{1}$ on $L_{0}$ already provide us with good reasons to establish that in the procedural level we are merely using FOL as a logical system, whereas in the theoretical level we are using FOL as a part of a metaphysical theory. This distinction is crucial for it allows us to maintain that FOL functions in two distinct ways in both cases wherein the former is independent of the latter. If such is the case then there is a scenario where a regimented theory is not dependent on $L_{2}$.

As I see it, this can also be used as a counterargument to Tahko's position that logical laws ought to be seen as metaphysical principles. This is so, for as we mentioned in the previous section, he maintains that logical languages have their limitations (i.e., the limitations of modal logic). Tahko, in this case, can also be seen as distinguishing between the procedural and theoretical role of a logical language. This is more evident as he states:

(P)lausibly there can be only one true logic, that is, only one logic which fully corresponds with reality. This naturally follows from the idea that reality is one and undivided, that is, reality has a rigid structure and this structure can be described with a single formal system, if it can be described so at all...Naturally it is not very straight-forward to determine what this one true logic is..., in fact we can probably never fully characterize it. (Tahko, 2009: 44)

If we juxtapose this with his view that the logical principles of $L_{1}$ are mind-independent (i.e. they are not dependent on our rationality), we can understand why he claims that we cannot arrive at "the one true logic." (Tahko, 2009: 44). Though I agree with him that we may not arrive at "the one true logic" since our cognitive capacities prevent us 
from fully accessing the structure of the external world, this position does not sit well with his claim that our conception of the external world is based on our pre-theoretical intuitions about it. If our cognitive capacities are limited then it must also be the case that our pre-theoretical intuitions about external reality are limited or, in the worst-case scenario, completely wrong. The problem for Tahko now is to show that what we referred to as the theoretical usage of $L_{1}$ (i.e., the laws of $L_{1}$ are seen as metaphysical principles) is indispensable in our regimented theories.

As I see it, if we wish to address this problem we ought to show that the containment of a regimented theory in $L_{2}$ is indispensable in science. We have already provided initial grounds for this in the previous section when we maintained that physicalism is dependent on the metaphysical principles of $L_{1}$. Yet, to strengthen our claim, it is crucial to establish that the procedural role of $L_{1}$ in our regimented theories is also dependent on metaphysical principles. Although our emphasis in showing the procedural dependence of our scientific theories in $L_{1}$ is based on how its syntax allows inferences to be initiated and to proceed in the revision of a regimented theory, the integration between the procedural and the theoretical usage of $L_{1}$ occurs when the usage of the latter is grounded on how the content of $L_{0}$ is related to the world. In other words, the theoretical usage of FOL is indispensable to science for the procedural usage of FOL is dependent on the metaphysical grounding that a logical system is supposed to provide regarding the relationship of our scientific data and the external world. $L_{1}$ in its procedural usage provides metaphysical grounding since it supplies a "metaphysical explanation" (that allows us to show that) when some $x$ is grounded in some $y \ldots y$ explains $x$... (in a way that) $y$ is generally thought to be somehow prior to that of $x^{\prime \prime}$ (Tahko, 2016: 93). In other words, even in the procedural usage of $L_{1}$, the structure that it provides to our scientific theories is what allows these theories to capture the structure of the external world. In this case, we can still retain the view that a regimented theory is based on $L_{2}$.

\section{Conclusion}

At this juncture, we are now in a position to provide the general outlines of a revised version of $Q N$. In line with what we have discussed so far, we can see that QN can only retain its naturalist stance if it recognizes that the scientific language that we are continuously creating to specify the physical-state predicates of the objects in the external world is dependent on $L_{2}$ for it provides the basis for the possibility of the existence of a space 
where "space displacement, shape change, and chemical change" may occur (Quine, 1961: 199). For example, when we attribute the predicate "is a brain state" to the singular term "consciousness," we can only envision the attribution of this predicate to the singular term if there is an initial presupposition that there is a space possible for the existence of the object represented by our singular term.

Metaphysical possibility plays a crucial role here for it sets the limitations for how we can envision the external world and its objects. Tahko describes how such is the case in the following:
(M)etaphysics deals with possibilities-metaphysical possibilities-but is not able to determine what is actual without the help of empirical research. However, it is crucial for this account that empirical knowledge in itself is not able to determine what is actual either, for a priori inquiry is needed to delimit the space of possibilities from which the actual structure of reality can be identified by empirical means. Consequently, a priori inquiry is necessary and prior to knowledge of actuality, because without this metaphysical delimitation of what is possible, the space of possibilities would be too vast to handle. So, it is this a priori delimitation of space possibilities which enables us to pick out just the genuine metaphysical possibilities from the enormous space of conceivable yet metaphysically impossible things. (Tahko, 2012: 39)

To clarify Tahko's position above, let us return to our claim that both LNC and LEM are fundamental metaphysical principles that govern the state of affairs in the external world. These principles help us to delimit the space of possibilities that should be the object of our empirical inquiries. For instance, LNC allows us to posit that if we wish to understand consciousness, we cannot maintain that an entity is conscious and not conscious at the same time. In addition, LEM allows us to claim that the proposition "a rabbit is conscious" can only have one truth-value (i.e., either true or false and nothing in between). In these examples, we can see that what is metaphysically possible is either metaphysically necessary or metaphysically contingent. Our claim that an entity cannot have the same mutually exclusive properties above is metaphysically necessary by virtue of LNC's status as a fundamental metaphysical principle. On the other hand, our claim that the proposition above can only have two truth-values is metaphysically contingent for 
its truth-value is dependent on further empirical proof. In this context, posits which are neither metaphysically necessary nor metaphysically contingent are considered to be metaphysically impossible. They are metaphysically impossible since even if they are conceivable, they violate the basic principles that govern the external world.

To further clarify the distinction between what is metaphysically possible and impossible, it is helpful to introduce the concept of epistemic possibility. In our case, we will say that $x$ is epistemically possible so long as an epistemic agent can believe that it can possibly be true. For instance, it is epistemically possible that the proposition "rabbits are a silicon-based life form" is true. Yet, even if it is epistemically possible, it is not necessarily metaphysically possible. The reason for this lies in the former's dependence on an agent's belief and the latter's dependence on the state of affairs in the external world. As you can see, an offshoot of this characterization of metaphysical possibility is that it presupposes that metaphysics and science can provide us with a partial characterization of an object's nature. Hence, since it is not in the nature of animalbased life forms on earth to be silicon-based then the proposition above is not metaphysically possible. In addition, we cannot say that it is metaphysically contingent since it is a part of the nature of rabbits to be carbon-based life forms. That is, if we find rabbit-like creatures that are silicon-based life forms then they are not rabbits but an entirely different entity. We are warranted in claiming that they are an entirely different entity, for instance, since LNC is a manifestation of one of the principles that govern the external world. That is, external reality is built in such a way that does not allow an entity to be both a carbon-based and silicon-based life form. As you can see, it is useful to introduce the concept of epistemic possibility when we attempt to demonstrate how metaphysics limits the space of possibilities that can be the object of our scientific inquiries for this shows us that the hypotheses that we ought to test in science should be based on a priori metaphysical principles and not just based on their mere conceivability.

One of the repercussions of adopting the relationship we described between metaphysics and science above is that we are able to retain QN's naturalist stance. Metaphysics here does not hold the status of a first philosophy for even if it sets the parameters for scientific inquiry, its development as well as the confirmation of its own hypotheses are dependent on the byproducts of our scientific inquiries. QN is also able to retain its physicalist hypothesis. Yet, in order to do so, it must 
accommodate metaphysical a priori truths in its epistemology. Again, if it aims to initiate the test for its physicalist hypothesis regarding the external world, its background assumptions must follow the metaphysical principles provided by $L_{2}$. On a different note, if it aims to create a regimented language where the predicates of its singular terms are set and determined by spatio-temporal conditions, it must be based on the metaphysical possibility of the existence of these objects and their possession of these properties. This thereby leads us to a modification of QN's epistemology. We now have the distinction between a priori and a posteriori truths in QN. Our hypotheses regarding objects (e.g., consciousness is a brain state) starts with an a priori account of an object's identity which is later confirmed or disconfirmed based on empirical evidence.

Our argument thereby leads to a slight modification of QN. Now it still retains its naturalist stance, but it allows the inclusion of both metaphysical a priori statements and a posteriori statements within our regimented theories. If my assessment of QN is tenable, which I consider it to be the case, then one of the tasks that we are confronted with now is providing a more extensive description of how the inclusion of metaphysical a priori truths affects QN's appraisal of other problems in philosophy. What I have provided in this conclusion is a rough outline of how this can be done. As I see it, providing a more extensive revision of QN is a worthwhile task to pursue not only because it gives us a more specific formulation of a more charitable version of $\mathrm{QN}$ but also because it will have numerous repercussions in other fields in philosophy (e.g., on the issue of qualia).

\section{REFERENCES}

Dummett, Michael. Origins of Analytical Philosophy. London: Bloomsbury, 1994. Print.

Fogelin, Robert J. “Aspects of Quine's naturalized epistemology." The Cambridge Companion to Quine. Ed. Roger F. Gibson, Jr. Cambridge: Cambridge University Press, 2006. 19-46. Print. Cambridge Companions to philosophy.

Gibson, Roger. “The Key to Interpreting Quine." Philosophy of Quine: general, reviews, and analytic/synthetic. Ed. Dagfinn Føllesdal, New York: Garland publishing, 2000. 25-38. Print. 
Harris, James. Against Relativism: a philosophical defense of method. Chicago: Open Court, 1997. Print.

Hylton, Peter. Quine. London: Routledge, 2007. Print

Mittelstaedt, Peter and Paul Weingartner. Laws of nature. Germany: Springer, 2005. Print.

Morganti, Matteo, y Tuomas E. Tahko. «Moderately naturalistic metaphysics». Synthese 194.7 (2017): 2557-2580. Web.

Quine, W.V.O. Ontological relativity and other essays. New York: Columbia: Columbia University Press, 1969. Print. The John Dewey essays in philosophy no. 1

Quine, W.V.O. From a logical point of view. Harvard: Harvard University Press, 1961.Print.

Quine, W.V.O. Word and object. Massachusetts: MIT Press, 1960. Print.

Sinclair, Robert. Science and Sensibilia by W. V. Quine: The 1980 Immanuel Kant Lectures. Cham: Springer International Publishing Imprint, Palgrave Macmillan, 2019. Print.

Tahko, Toumas. An introduction to metametaphysics. Cambridge: Cambridge University Press, 2016. Print.

Tahko, Toumas. Contemporary Aristotelian metaphysics. Cambridge: Cambridge University Press, 2012. Print.

Tahko, Toumas. "The law of non-contradiction as a metaphysical principle." Australasian Journal of Logic 7 (2009): 32-47. Print.

Como citar:

Boongaling, Pamela Ann J. "Is Quinean naturalism dependent on the metametalanguage of metaphysics?". Discusiones Filosóficas. Ene.-Jun. 36. 2020:39-52. DOI: 10.17151/difil.2020.21.36.4 